\title{
Novel protocol for lutein extraction from microalga Chlorella vulgaris
}

\author{
D'Este, Martina; De Francisci, Davide; Angelidaki, Irini
}

Published in:

Biochemical Engineering Journal

Link to article, DOI:

10.1016/j.bej.2017.06.019

Publication date:

2017

Document Version

Peer reviewed version

Link back to DTU Orbit

Citation (APA):

D'Este, M., De Francisci, D., \& Angelidaki, I. (2017). Novel protocol for lutein extraction from microalga Chlorella vulgaris. Biochemical Engineering Journal, 127, 175-179. https://doi.org/10.1016/j.bej.2017.06.019

\section{General rights}

Copyright and moral rights for the publications made accessible in the public portal are retained by the authors and/or other copyright owners and it is a condition of accessing publications that users recognise and abide by the legal requirements associated with these rights.

- Users may download and print one copy of any publication from the public portal for the purpose of private study or research.

- You may not further distribute the material or use it for any profit-making activity or commercial gain

- You may freely distribute the URL identifying the publication in the public portal

If you believe that this document breaches copyright please contact us providing details, and we will remove access to the work immediately and investigate your claim 
Novel protocol for lutein extraction from microalga Chlorella vulgaris

Martina D'Este ${ }^{\mathrm{a}}$, Davide De Francisci ${ }^{\mathrm{a} 1}$, Irini Angelidaki ${ }^{\mathrm{a}}$

a. Technical University of Denmark, Department of Environmental Engineering, Building 113, DK-2800 Kgs. Lyngby, Denmark.

Highlights

- A novel method for the extraction of lutein from microalgae was developed.

- Water was replaced by ethanol in the saponification step.

- Saponification and extraction were conducted simultaneously.

- Quantity of lutein extracted increased 3 folds compared to conventional methods.

- Final lutein purity increased from $73.6 \%$ to $93.7 \%$.

\section{ABSTRACT}

Lutein is a pigment generally extracted from marigold flowers. However, lutein is also found in considerable amounts in microalgae. In this study a novel method was developed to improve the extraction efficiency of lutein from microalga $C$. vulgaris. Differently from conventional methods, ethanol was used instead of water in the saponification step, which was conducted simultaneously to the solvent extraction, performed using dichloromethane. The amount of lutein extracted from $C$. vulgaris dried biomass increased more than threefold, from $0.20 \pm 0.00 \mathrm{mgLutein} / \mathrm{gDM}$ to $0.69 \pm 0.08 \mathrm{mgLutein} / \mathrm{gDM}$. Lutein purity was increased from $73.6 \%$ to $93.7 \%$ by decreasing the ethanol-water ratio from $85 \%$ to $50 \%$ in the resolubilization step. The novel method was also tested with tetrahydrofuran. The extraction proved to be again more effective than the conventional one; however

\footnotetext{
${ }^{1}$ Corresponding author. E-mail address: dadf@env.dtu.dk (D. De Francisci)
} 
dichloromethane outperformed tetrahydrofuran in terms of quantity and purity of the recovered lutein.

Keywords: Lutein; Chlorella vulgaris; extraction; saponification; dichloromethane

\section{Introduction}

Lutein is a yellow xanthophyll, member of the carotenoid group. It is one of the predominant carotenoids present in the macular region of the human eye, being involved in the protection against light-induced retinal damage and age-related macular degeneration (AMD)[1,2]. Lutein assumption also prevents some types of cancer [3] and cardiovascular disease [4]. Moreover, it can contribute to human bone health [5]. Lutein is also a fundamental and an established feed additive in the poultry industry to brighten the color of chicken skin and of egg yolk [6].

Lutein is synthesized only by photosynthetic organisms like land plants and microalgae [7]. The worldwide market for this pigment is steadily increasing, and marigold flowers are currently the main source for the extraction and production of lutein. Microalgae have several advantages over this flower for lutein production: first of all, a higher lutein content and a faster growth rate [8] and the fact that they can be grown all year on infertile land and therefore without competition with arable crops [9]. In spite of these advantages, there are still several limitations that hinder the exploitation of this biomass for lutein production. Besides improving microalgae cultivation technologies, to bring the production of lutein from this biomass into reality it is fundamental to improve and optimize the related downstream processes, in particular extraction. 
Extraction protocols from microalgae generally involve the two following separated initial steps: 1) saponification, performed with an aqueous $\mathrm{KOH}$ solution to ensure a $\mathrm{pH}$ value of approximately 12 , needed to convert lutein fatty acid esters into free lutein, 2) solvent extraction, performed using different organic solvents combined with a cell disruption technology [10-12].

The majority of the studies have so far focused on finding an optimal solvent for highest extraction efficiency; a solvent that at the same time would be compatible with the utilization of lutein for food and feed. Optimal solvents have so far being identified in dichloromethane (DCM) and tetrahydrofuran (THF) [11,13]. According to the Department of Health and Human Services, Food and Drug Administration (FDA) [14], DCM and THF should be limited for commercial production of carotenoids for human consumption, differently from ethanol. Further steps in the extraction protocols are in fact devoted to the elimination of the solvent by evaporation.

Lutein extraction protocols also aim to eventually remove impurities and other unwanted pigments to achieve the highest possible purity [11].

Aim of the present work was to develop an improved method for lutein extraction compared to the conventional ones, in order to achieve higher yield and purity and, at the same time, reduce the extraction time. In the new protocol we tested the replacement of water with ethanol in the saponification process. Moreover, we introduced the simultaneous saponification and extraction step. The two solvent tested were DCM and THF.

\section{Materials and Methods}




\subsection{Chemical, reagents and biomass}

All chemicals used in this work were of analytical grade and were purchased from Sigma Aldrich ApS (Brøndby, Denmark). Lutein standard (concentration $0.804 \mathrm{mg} / \mathrm{L}$ ) was obtain by DHI Lab Products (Hørsholm,Denmark). Freeze-dried C. vulgaris biomass was supplied by Alpha-Biotech (France).

\subsection{Total pigments extraction}

The extraction of the hydrophobic pigments was performed with $2 \mathrm{mg}$ of freeze-dried biomass using $3 \mathrm{ml}$ of $95 \%$ acetone followed by $10 \mathrm{~min}$ of sonication (Branson 3510MT) in ice bath. This solvent was employed due to its low specificity and therefore to obtain a qualitative profile of the pigments present in the chosen microalgal biomass. The supernatant was separated from the residual biomass by centrifugation at 13,000 rpm for 10 min and analyzed using a high performance liquid chromatography (HPLC) system. The separation was achieved at $60^{\circ} \mathrm{C}$ with a HPLC (Dionex UltiMate 3000, Thermo Scientific, USA) equipped with a Zorbax Eclipse plus C8 RRHD $1.8 \mu \mathrm{m} 3.0 \times 150 \mathrm{~mm}$ column (Spherisorb-ODS1 Waters, Milford, MA, USA). The mobile phase consisted of (A) methanol/28 mM TBAA (tert-Butyl acetoacetate), $\mathrm{pH} 6.5$ (70/30) and (B) methanol and the flow rate was $0.3 \mathrm{ml} \mathrm{min}{ }^{-1}$. Detection utilized UV-VIS at $450 \mathrm{~nm}$. Samples and standards were dissolved in $100 \%$ ethanol and filtered by $0.22 \mu \mathrm{m}$ filters. After filtering a buffer was added in 1:3 sample/buffer ratio, using $28 \mathrm{mM}$ TBAA pH 6.5 .

\subsection{Conventional lutein extraction protocol (A)}

The main steps of the conventional extraction protocol (A) are summarized in Figure 1. 
For the saponification process to $1 \mathrm{~g}$ of microalgal biomass were added $2.5 \mathrm{ml}$ of $10 \mathrm{M}$ $\mathrm{KOH}$ containing $2.5 \%(\mathrm{w} / \mathrm{v})$ ascorbic acid. The mixture was incubated for $10 \mathrm{~min}$ at $60{ }^{\circ} \mathrm{C}$.

In the second step, $10 \mathrm{ml}$ of DCM were added. The mixture was placed in a sonicator bath for 1 hour and afterwards agitated at $300 \mathrm{rpm}$ for 2 hours in an orbital shaker. After brief vortexing the mixture was centrifuged for $5 \mathrm{~min}$ at $4000 \mathrm{rpm}$ and the supernatant was collected. This step was repeated until the extract was almost colorless and all extracts were combined (in total approximately $60 \mathrm{~mL}$ of DCM were added). Afterwards distilled water of the same volume as dichloromethane was added and stirred in a beaker for 4-5 minutes. This step was performed in order to separate the lutein containing fraction from the hydrosoluble pigments. The organic phase was then dried using a rotary evaporator, set at $40^{\circ} \mathrm{C}$. The residue was redissolved in $7 \mathrm{ml}$ of $85 \%$ aqueous ethanol (v/v). Hexane was added to the mixture in the ratio $1: 4(\mathrm{v} / \mathrm{v})$ and, after brief vortexing, was removed to eliminate the fat soluble contaminants. Water was then added to bring the final concentration to $8.5 \%$ ethanol $(\mathrm{v} / \mathrm{v})$ and the mixture was then centrifuged at $13000 \mathrm{rpm}$ for 10 minutes. The lutein precipitated was then resuspended in $100 \%$ ethanol.

For each extraction process samples for HPLC analyses were taken from all the extracts combined $(60 \mathrm{~mL}$ DCM); after the rotary evaporation step, following the addition of $85 \%$ ethanol (Figure 1). The entire procedure was performed in triplicates.

\subsection{Novel saponification and extraction protocol (B)}

The main steps of the novel extraction protocol (B) are summarized in Figure 1.

For this novel protocol the saponification and the extraction steps were conducted simultaneously. To $1 \mathrm{~g}$ of microalgal biomass $2.5 \mathrm{~mL}$ of ethanolic $\mathrm{KOH} 2 \mathrm{M}$ and $10 \mathrm{ml}$ of 
DCM were added. The mixture was placed in a sonicator bath for 1 hour and afterwards agitated at $300 \mathrm{rpm}$ for 2 hours in an orbital shaker. At this point another $2.5 \mathrm{~mL}$ of ethanolic $\mathrm{KOH} 2 \mathrm{M}$ were added and, after brief vortexing, the mixture was centrifuged for 10 min at $4000 \mathrm{rpm}$ and the supernatant was collected. At this point the extraction was repeated by adding only DCM (in total $60 \mathrm{ml}$ of DCM were used, in order to match the quantity used in the previous protocol). The organic phase was then dried using a rotary evaporator, set to $40^{\circ} \mathrm{C}$. The residue was redissolved in $7 \mathrm{ml}$ of $50 \%$ aqueous ethanol (v/v). This solution was stirred for 10 minutes and centrifuged at $13000 \mathrm{~g}$. The supernatant was collected and the pellet resuspended in 100\% ethanol $(7 \mathrm{~mL})$.

For each extraction process samples for HPLC analyses were taken from all the extracts combined (60mL DCM); from the organic fraction after the cleaning water step; after the rotary evaporation step, following the addition of 50\% ethanol (Figure 1). The entire procedure was performed in triplicates.

Once determined that this protocol resulted in a higher extraction efficiency compared to the conventional one and also for being less time consuming, the same procedure was repeated replacing DCM with THF (method C) in order to compare the respective lutein quantities.

\subsection{Quantification of lutein}

The lutein extracts were analyzed by HPLC as described in Section 2.2. The lutein content was detected by measuring absorbance at the wavelength range of $350-700 \mathrm{~nm}$. Two absorbance wavelengths were used (450 and $665 \mathrm{~nm}$ ) and the maximal absorbance (450 $\mathrm{nm}$ ) was chosen for quantification of lutein extracts. 
Lutein was identified using Chromeleon 7.2 Chromatography Data System (CDS) software by comparison with a library of pigments spectra. Lutein was quantified using a calibration curve generated with different quantities of lutein standard.

Purity of lutein was determined comparing the peak area of the lutein with the area of the other peaks in the chromatogram.

The lutein quantity for each sample was calculated by using the following equation:

Lutein quantity $\left(\frac{m g}{g D M}\right)=\frac{\text { Lutein concentration }\left(\frac{m g}{L}\right) \times \text { Volume of solution }(L)}{\text { Drycell weight }(g)}$

\subsection{Statistical analysis}

Data was analyzed with a one-way Analysis of Variance (ANOVA) followed by Tukey's test $(p<0.05)$ to evaluate if there were significant differences among the results obtained for different extracts. The software used to carry out the statistical analyses was OriginPro2016 (OriginLab Corporation, USA).

\section{Results and Discussion}

\subsection{Pigments composition}

Figure 2 shows the pigment composition profile of the $C$. vulgaris biomass tested in this study. The chromatogram shows high heterogeneity of the hydrophobic pigments, with the most abundant ones being lutein (Figure 2, peak 3), chlorophyll a (Figure 2, peak 4) and chlorophyll b (Figure 2, peak 5). Therefore, a procedure to selectively extract and purify lutein is needed. 


\subsection{Summary of the differences between the conventional and the novel methods}

A novel protocol was developed and tested on C. vulgaris biomass. In this protocol, water was replaced with ethanol in the saponification process, based on the assumption that, being lutein insoluble in water and $100 \%$ soluble in ethanol, employing this solvent would minimize partial precipitation of the pigment in this specific step. The saponification and the extraction steps were also combined in order to simplify the entire process as it was done for marigold flowers $[15,16]$. The validity of this improved protocol was assessed by performing the extraction both with the conventional extraction method (saponification with aqueous $\mathrm{KOH}$ and separated from the solvent extraction) and the one developed in this work, and eventually comparing the results. DCM was employed as solvent for this comparison as it was the one most widely used for to extraction of lutein from microalgae. After having proved that these modifications hugely improved the conventional protocol as hypothesized, THF was also tested in the same optimized conditions in order to determine whether this solvent could outcompete DCM as the elective organic solvent for the extraction of this pigment.

\subsection{Saponification and extraction}

The differences in the initial steps of the two extraction protocols (i.e., conventional method and novel method) are summarized in Figure 1. The chromatographic analyses (Figure 3) showed that, due to the introduced modifications but most probably mainly for the replacement of water with ethanol, the quantity of lutein extracted increased of a remarkable 3 folds, from $0.31 \pm 0.06 \mathrm{mgLutein} / \mathrm{gDM}$ (conventional method) to $1.00 \pm 0.15$ 
(Table 1, step 1). Most probably the reason of such an increase is imputable to the different solubility of lutein in water and ethanol ( 0 and $100 \%$ respectively). The utilization of ethanol instead of water in this critical step has probably resulted into a higher conversion of lutein fatty acid esters into free lutein and this despite the much lower concentration of $\mathrm{KOH}$ that guaranteed anyway the maintenance of $\mathrm{pH}$ at 12 for the entire process. In both cases the purity of lutein amounted to approximately $70 \%$ due to the presence in the extract of other pigments, mainly neoxanthin and violaxanthin, Figure 3.

\subsection{Effect of different ethanol concentration on the final purity}

The final quantity of lutein achieved using protocol B was $0.69 \pm 0.08 \mathrm{mgLutein} / \mathrm{gDM}$, more than 3 times the amount achieved with protocol A $(0.20 \pm 0.00 \mathrm{mgLutein} / \mathrm{gDM})$. All the results are summarized in Table 1 and can be visualized in Figure 5. It is also noteworthy that in the conventional protocol more lutein is lost through the different purification steps compared to protocol B (Table 1). The rotary evaporator step was used to completely remove the DCM before resolubilizing the dried pigments mixture, mainly constituted by lutein, in a water-ethanol solution. The importance of completely removing DCM is due to its toxic nature even in remote traces, which is inappropriate in drug and food products [14]. This step was also necessary for increasing the purity of lutein. Indeed, by choosing an appropriate ethanol-water ratio, it is possible to exploit the physicochemical properties of lutein to selectively precipitate this pigment while keeping the others in solution. Lutein being completely insoluble in water, maximizing the ethanol in the resolubilization step enables a higher lutein recovery. Our results show (Figure 4) that a 
$50 \%$ ethanol-water ratio translates into a much higher lutein purity compared to $8.5 \%$ ratio utilized in the conventional protocol, with a purity exceeding $90 \%$.

In Figure 4 is possible to notice that neoxanthin and violaxanthin were almost completely removed from the mixture. Another important alteration in comparison with the conventional extraction method is the removal of the hexane step from the protocol. This is an additional advantage of the novel protocol as hexane is also considered toxic for food and drugs.

\subsection{Effect of different solvents on the novel extraction protocol}

Once determined that protocol B is strongly preferable compared to A both in terms of quantity and quality of lutein recovered, the same protocol was tested using THF instead of DCM. THF was chosen because this solvent was proven to be compatible for the solubilization and purification of lutein from microalgae in previous works [13]. The results showed that DCM was still the solvent of election for this process as protocol B corresponds a quantity of lutein equal to $0.69 \pm 0.08 \mathrm{mgLutein} / \mathrm{gDM}$ compared to $0.41 \pm$ $0.00 \mathrm{mgLutein} / \mathrm{gDM}$ of THF (Table 1, step 3 and Figure 5). Moreover protocol B achieves a higher purity than protocol C (93.7\% and $87.4 \%$ respectively) (Table 1$)$.

\subsection{Lutein yield}

In literature, the total lutein content of microalgae biomasses are calculated using extraction protocols whit diethyl ether or DCM as solvent $[10,13]$. This specific value is necessary to calculate the final extraction yield. In Chan et al. the quantity is extracted with DCM and diethyl ether is not significantly different. In Chen et al. THF is found to outperform diethyl ether. None of these methods utilizes ethanol in the saponification step which, according to 
our results and to a vast number of papers in which lutein is extracted from Marigold flowers $[17,18]$, increases remarkably the solvent performance. Indeed, the higher lutein solubility in ethanol enables a lower lutein precipitation in the saponification step, with a consequent higher yield. Furthermore, always according to our results, DCM outperforms THF significantly. Based on all these considerations it was concluded that the amount of

lutein extracted from the first step of protocol B (DCM as extraction solvent and ethanol in the saponification process) is the most accurate and therefore the one to be considered as total lutein content of this specific biomass $(1.00 \pm 0.15 \mathrm{mg} / \mathrm{gDM})$. Based on this assumption the final yields resulted to be 20,69 and $41 \%$ for protocol A, B and C, respectively. Moreover, considering a microalgal biomass productivity of $0.54 \mathrm{~g} / \mathrm{L} / \mathrm{d}$ as reported in the study of Lin et al. (2015), a lutein productivity of $0.11,0.37$ and $0.22 \mathrm{~g} / \mathrm{L} / \mathrm{d}$ could be achieved in our work for protocol A, B and C, respectively.

\section{Conclusion}

In this work a novel protocol for the extraction of lutein from microalgae was developed. In the saponification step water was replaced with ethanol to minimize loss due to precipitation. Also, saponification and solvent extraction were performed simultaneously. Lutein yield, quantitatively and qualitatively, increased significantly in respect to conventional protocols, both when using DCM or THF as extraction solvent. The use of DCM translated into a better performance compared to THF.

\section{Acknowledgements}

This work resulted from the BONUS Microalgae project was supported by BONUS (Art 185), funded jointly by the EU and the Danish Agency for Science, Technology and 
Innovation (DASTI), the Estonian Environmental Investment Centre (KIK) and The

Swedish Foundation for Strategic Environmental Research (MISTRA).

We thank Satomi Matsuura and Mikael Emil Olsson for the technical support.

\section{References}

[1] F. Granado, B. Olmedilla, I. Blanco, Nutritional and clinical relevance of lutein in human health., Br. J. Nutr. 90 (2003) 487-502. doi:10.1079/BJN2003927.

[2] C.J. Chiu, A. Taylor, Nutritional antioxidants and age-related cataract and maculopathy, Exp. Eye Res. 84 (2007) 229-245. doi:10.1016/j.exer.2006.05.015.

[3] P. Astorg, Food carotenoids and cancer prevention: An overview of current research, Trends Food Sci. Technol. 8 (1997) 406-413. doi:10.1016/S0924-2244(97)01092-3.

[4] J.H. Dwyer, M. Navab, K.M. Dwyer, K. Hassan, P. Sun, a Shircore, S. Hama-Levy, G. Hough, X. Wang, T. Drake, C.N. Merz, a M. Fogelman, Oxygenated carotenoid lutein and progression of early atherosclerosis: the Los Angeles atherosclerosis study., Circulation. 103 (2001) 2922-2927. doi:10.1161/01.CIR.103.24.2922.

[5] T. Tominari, C. Matsumoto, K. Watanabe, M. Hirata, F.M.W. Grundler, M. Inada, C. Miyaura, Lutein, a carotenoid, suppresses osteoclastic bone resorption and stimulates bone formation in cultures, Biosci. Biotechnol. Biochem. 8451 (2016) 15. doi:10.1080/09168451.2016.1243983.

[6] M. Grashorn, Feed Additives for Influencing Chicken Meat and Egg Yolk Color, Elsevier Ltd, 2016. doi:10.1016/B978-0-08-100371-8.00014-2.

[7] C.B. Beck, An Introduction to Plant Structure and Development: Plant Anatomy for the Twenty-first Century, 2010. 
[8] J.H. Lin, D.J. Lee, J.S. Chang, Lutein production from biomass: Marigold flowers versus microalgae, Bioresour. Technol. 184 (2015) 421-428. doi:10.1016/j.biortech.2014.09.099.

[9] Y. Chisti, Biodiesel from microalgae beats bioethanol, Trends Biotechnol. 26 (2008) 126-131. doi:10.1016/j.tibtech.2007.12.002.

[10] M.C. Chan, S.H. Ho, D.J. Lee, C.Y. Chen, C.C. Huang, J.S. Chang, Characterization, extraction and purification of lutein produced by an indigenous microalga Scenedesmus obliquus CNW-N, Biochem. Eng. J. 78 (2013) 24-31. doi:10.1016/j.bej.2012.11.017.

[11] H.-B. Li, Y. Jiang, F. Chen, Isolation and Purification of Lutein from the Microalga Chlorella vulgaris by Extraction after Saponification, J. Agric. Food Chem. 50 (2002) 1070-1072.

[12] M.C. Cerón, I. Campos, J.F. Sánchez, F.G. Acién, E. Molina, J.M. FernándezSevilla, Recovery of lutein from microalgae biomass: Development of a process for Scenedesmus almeriensis biomass, J. Agric. Food Chem. 56 (2008) 11761-11766. doi:10.1021/jf8025875.

[13] C.Y. Chen, Jesisca, C. Hsieh, D.J. Lee, C.H. Chang, J.S. Chang, Production, extraction and stabilization of lutein from microalga Chlorella sorokiniana MB-1, Bioresour. Technol. 200 (2016) 500-505. doi:10.1016/j.biortech.2015.10.071.

[14] U.S.D. of H. and H. Services, F. and D. Administration, Tables and List Guidance for Industry Q3C, 2012. http://www.fda.gov/Drugs/GuidanceComplianceRegulatoryInformation/Guidances/d efault.htm\%5Cnhttp://www.fda.gov/BiologicsBloodVaccines/GuidanceCompliance 
RegulatoryInformation/Guidances/default.htm.

[15] F. Khachik, PROCESS FOR EXTRACTION AND PURIFICATION OF LUTEIN, ZEAXANTHIN AND RARE CAROTENOIDS FROM MARIGOLD FLOWERS AND PLANTS, 2003. doi:10.1016/j.(73).

[16] M. Hojnik, M. Škerget, Ž. Knez, Extraction of lutein from Marigold flower petals Experimental kinetics and modelling, LWT - Food Sci. Technol. 41 (2008) 20082016. doi:10.1016/j.lwt.2007.11.017.

[17] J. Vechpanich, A. Shotipruk, : Determination of Suitable Saponification and Crystallization Conditions, Sep. Sci. Technol. 46 (2010) 265-271. doi:10.1080/01496395.2010.506904.

[18] P. Boonnoun, T. Opaskonkun, P. Prasitchoke, M. Goto, A. Shotipruk, Purification of free lutein from marigold flowers by liquid chromatography, Eng. J. 16 (2012) 145155. doi:10.4186/ej.2012.16.5.145.

\section{Figure captions}

Figure 1: Schematic representation of the conventional (Protocol A) and novel (Protocol B) methods. Only the main steps are included. Samples for HPLC analyses were taken from the steps marked with an asterisk.

Figure 2: Chromatogram of the pigments extracted from C. vulgaris. Peaks: 1, neoxanthin; 2, violaxanthin; 3, lutein; 4, chlorophyll b; 5, chlorophyll a.

Figure 3: Chromatogram of crude lutein obtained by extraction with DCM with the conventional method (a) and with the novel one (b). Peaks: 1, neoxanthin; 2, violaxanthin; 3, lutein. 
Figure 4: Chromatogram of purified lutein obtained with DCM with the conventional method (a) and with the novel one (b). Peaks: 1, neoxanthin; 2, violaxanthin; 3, lutein.

Figure 5: Chromatogram of purified lutein obtained with the novel method using DCM (a) or THF (b) as solvent. Peaks: 1, neoxanthin; 2, violaxanthin is not present; 3, lutein. 


\begin{tabular}{|c|c|}
\hline Protocol A & Protocol B \\
\hline Algae biomass & Algae biomass \\
\hline $\begin{array}{c}\downarrow \\
\text { Saponification } \\
\text { 10M KoH } \\
2.5 \% \text { (W/v) ascorbic acid } \\
\left(60^{\circ} \mathrm{C} 10 \mathrm{~min}\right)\end{array}$ & \begin{tabular}{|c|} 
Saponification and \\
Extraction \\
$2 \mathrm{M}$ ethanolic $\mathrm{KOH}$ \\
DM
\end{tabular} \\
\hline$\downarrow$ & $\downarrow$ \\
\hline $\begin{array}{c}\text { Extraction } \\
\text { DCM }\end{array}$ & \begin{tabular}{|c|}
$\begin{array}{l}\text { Solvent removal } \\
\text { Rotary evaporator } 40^{\circ}\end{array}$ \\
\end{tabular} \\
\hline$\downarrow$ & $\downarrow$ \\
\hline \begin{tabular}{|l|} 
Solvent removal \\
Rotary evaporator $40^{\circ}$
\end{tabular} & \begin{tabular}{|c|} 
Resuspension \\
50\% Ethanol + \\
\end{tabular} \\
\hline & $\downarrow$ \\
\hline Resuspension & Precipitation + \\
\hline $85 \%$ Ethanol +1 & \\
\hline $\begin{array}{c}\text { Fat impurities } \\
\text { removal } \\
\text { Hexnc }\end{array}$ & \\
\hline$\downarrow$ & \\
\hline Precipitationt & \\
\hline
\end{tabular}


Figr-2

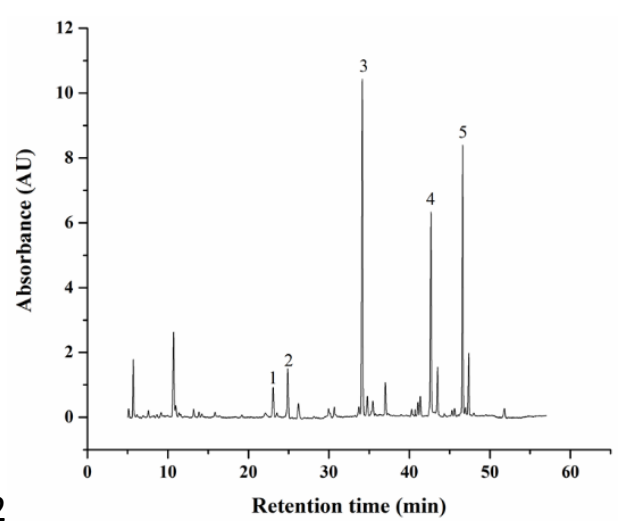




\section{Figr-3}

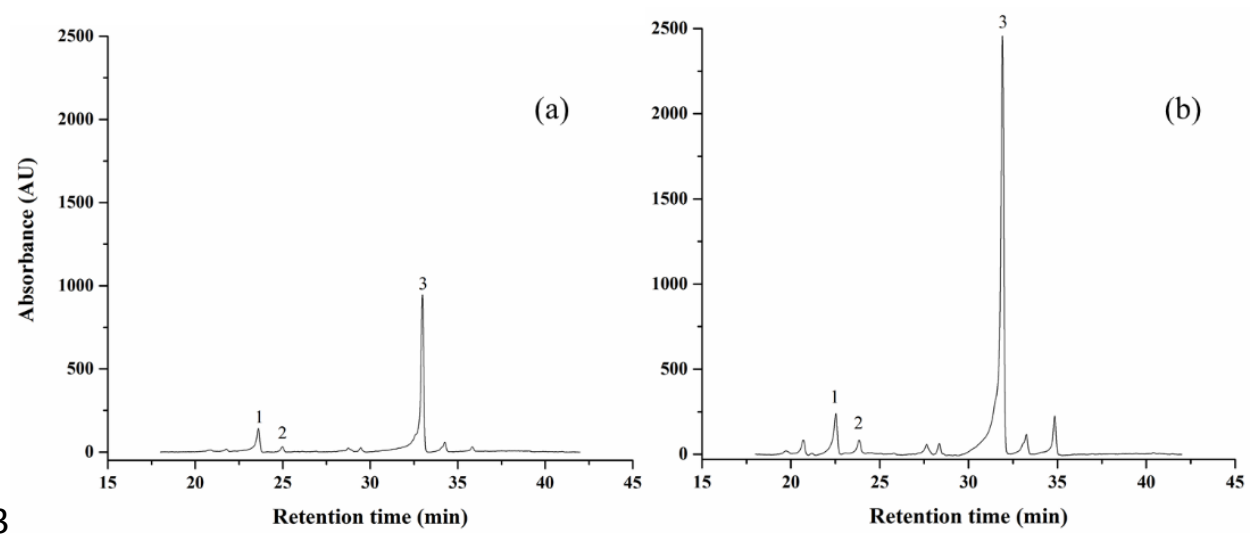


Figr-4
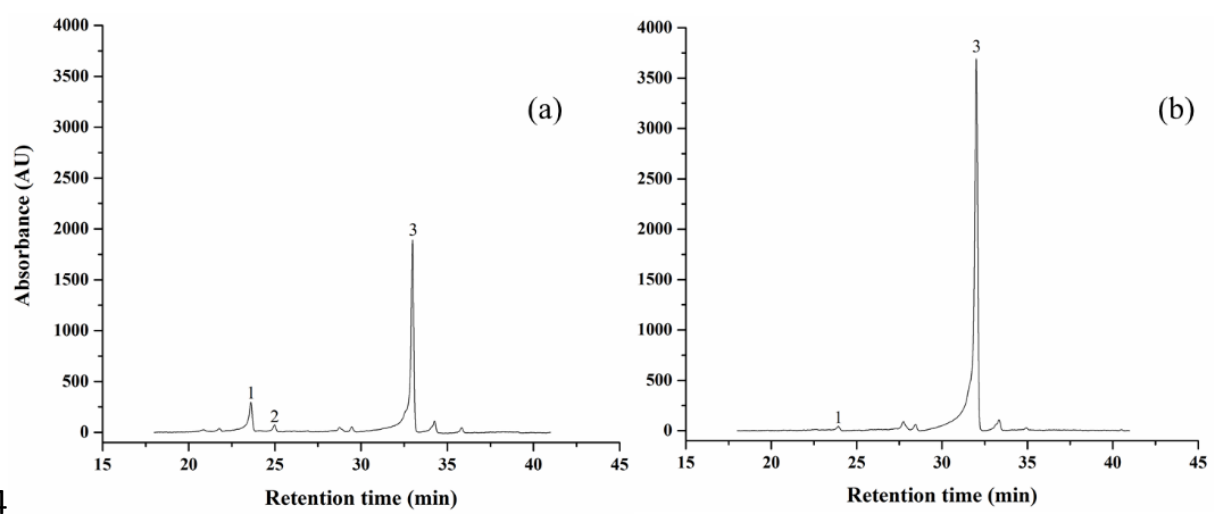


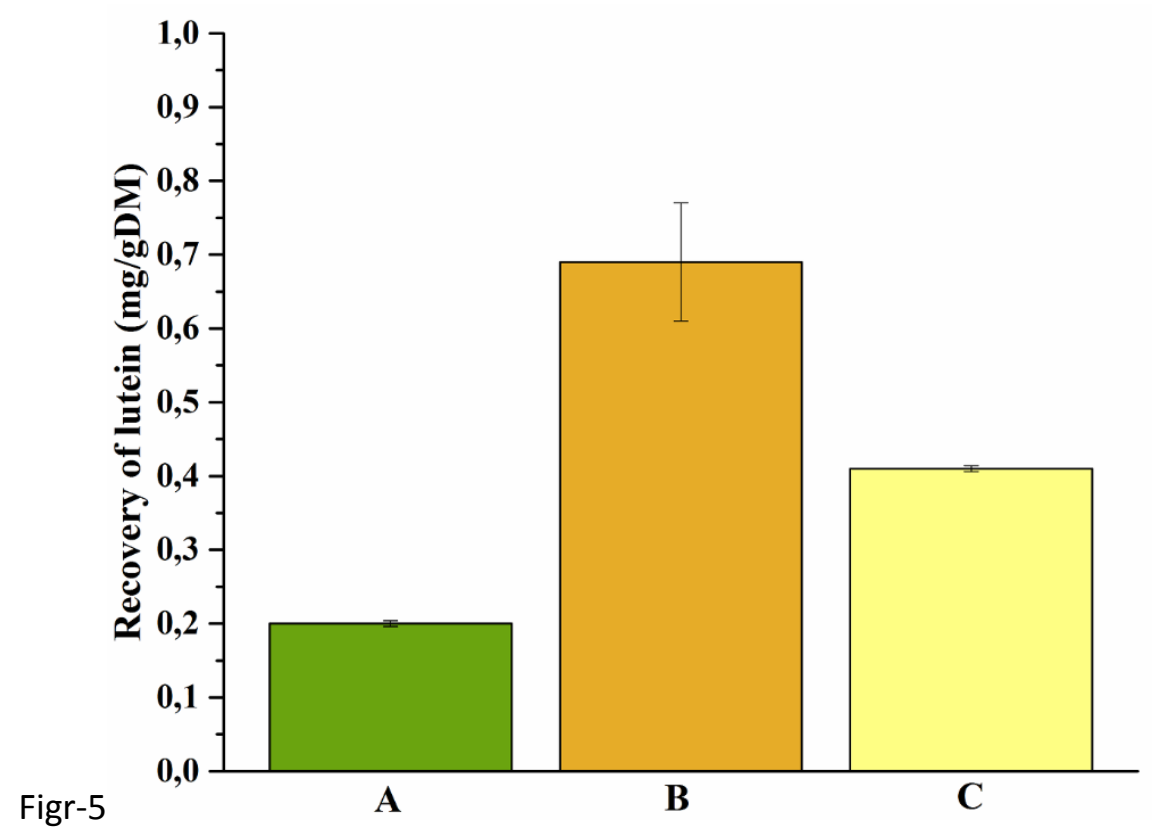


Table 1: Lutein extracted $\left(\mathrm{mggDM}^{-1}\right)$ and purity through the different purification steps in protocol A, B and C.

\begin{tabular}{ccccccccccc}
\cline { 2 - 9 } & \multicolumn{3}{c}{ Step 1 } & \multicolumn{3}{c}{ Step 2 } & \multicolumn{3}{c}{ Step 3 } \\
\cline { 2 - 9 } & $\begin{array}{c}\text { Protoc } \\
\text { ol A }\end{array}$ & $\begin{array}{c}\text { Protoc } \\
\text { ol } \\
\text { B }\end{array}$ & $\begin{array}{c}\text { Protoc } \\
\text { ol C }\end{array}$ & $\begin{array}{c}\text { Protoc } \\
\text { ol A }\end{array}$ & $\begin{array}{c}\text { Protoc } \\
\text { ol B }\end{array}$ & $\begin{array}{c}\text { Protoc } \\
\text { ol C }\end{array}$ & $\begin{array}{c}\text { Protoc } \\
\text { ol A }\end{array}$ & $\begin{array}{c}\text { Protoc } \\
\text { ol B }\end{array}$ & $\begin{array}{c}\text { Protoc } \\
\text { ol C }\end{array}$ \\
\hline $\begin{array}{c}\text { Lutein } \\
(\mathbf{m g} / \mathbf{g D} \\
\mathbf{M})\end{array}$ & $0.31 \pm$ & $1.00 \pm$ & $0.57 \pm$ & $0.33 \pm$ & $0.88 \pm$ & $0.53 \pm$ & $0.20 \pm$ & $0.69 \pm$ & $0.41 \pm$ \\
\hline $\begin{array}{c}\text { Lutein } \\
\text { purity } \\
(\%)\end{array}$ & 70.3 & 70.1 & 71.4 & 73.2 & 71.6 & 72.1 & 73.6 & 93.7 & 87.4 \\
\hline
\end{tabular}

